\title{
High Frequency Somatic Embryogenic Callus Induction and Plant Regeneration from Various Indica Rice Genotypes
}

\author{
Md. Enamul Hoque ${ }^{* 1}$ and John W. Mansfield ${ }^{2}$
}

'Biotechnology Division, Bangladesh Rice Research Institute, Gazipur-1701, Bangladesh

${ }^{2}$ Department of Agricultural Sciences Imperial College London, Wye campus, Ashford, Kent, TN25 5AH, UK.

\begin{abstract}
The paper evaluated the behavior of in vitro culture responses from a diverse set of Indica rice (Oryza sativa L.) genotypes. Significant differences were found in embryogenic callus induction frequency, callus growth and plant regeneration frequency when mature embryos of 11 cultivars, breeding lines and land races were compared. Genotype as well as plant growth regulator influenced the plant regeneration frequency. Callus induction frequency was not correlated with callus growth as well as plant regeneration frequency. The regenerated plants could grow to normal, fertile plants after they were successfully established in soil.
\end{abstract}

\section{Introduction}

Indica rice accounts for about $80 \%$ of total rice production and feeds more than two billion people, predominantly in developing countries (Jain 1997). The application of biotechnology has greatly enhanced rice breeding programs. Efficient plant regeneration in vitro is essential for the successful utilization of biotechnology in rice crop improvement (Hoque 2002). But it is often difficult to establish embryogenic cell cultures and to regenerate plants from these cultured cells especially those belonging to Indica subspecies (Chu and Croughan 1990, Jain 1997). Even within the Indica group, there are significant variations in the in vitro culture responses among different genotypes (Khanna and Raina 1998, Hoque and Mansfield 2004). The recalcitrant nature of this subspecies has, in fact, been a major limiting factor for the transfer of available useful genes (Toenniessen 1991).

\footnotetext{
* Corresponding author: e-mail: hoqueh2003@yahoo.com

Received Mar. 10, 2006 ; Accepted Nov. 9, 2006
}

Therefore, the identification and screening of useful cultivars for somatic embryogenic callus formation and subsequent plant regeneration in vitro are prerequisites in gene transfer and plant regeneration in rice biotechnology (Hoque and Mansfield 2004). Success in plant regeneration in vitro highly depends on plant genotype and explants used, in addition to culture conditions (Jain 1997). As genotypic effects are unavoidable, any strategy to improve plant regeneration in vitro must involve the use of appropriate explants for initiation of callus cultures and manipulation of culture conditions.

Establishment of embryogenic callus culture is required to obtain somatic embryos and subsequently to achieve plant regeneration in vitro (Hoque 2002). Embryogenic callus has been obtained from almost all the explant types in rice (Jain 1997). However, significant variation was observed in embryogenic callus production, somatic embryogenesis and subsequent plant regeneration from different origin (Rueb et al. 1994). Immature embryos were found to be superior explant in term of plant regeneration in vitro (Jain 1997). However, immature embryos require a specific developmental stage of the plant from which they are collected (Lörz et al. 1988). Moreover, the response of immature embryo to regeneration was affected by the conditions under which donor plants are grown (Vasil et al. 1993, Jain 1997). Since this explant source is restricted to a short period of the growth cycle of the rice plant as well as depends on the physiological condition of the donor plants, other explants such as mature embryos, which are available throughout the year, are more suitable from the logistical point of view for rice tissue culture, provided that a high frequency of regeneration can be achieved (Rueb et al. 1994). Above all, the embryogenic calli obtained from mature embryos are effective for genetic transformation (Hoque 2002, Lee et al. 2002). Therefore the purpose of the study described in this paper was to attempt to develop an efficient system for induction of somatic embryogenic calli and regeneration of plants in vitro from 
mature embryos of a diverse set of Indica rice genotypes, which will be useful for different biotechnological approaches in South-East Asian rice crop improvement programs (e.g. genetic transformation, somaclonal variation and somatic hybridization).

\section{Materials and methods}

\section{Callus Induction}

Eleven Bangladeshi Indica rice genotypes with diverse genetic background were used for this study (Table 1). Mature healthy seeds were selected and dehusked as experimental material. The seeds were first soaked in $70 \%$ (v/v) ethanol for $3 \mathrm{~min}$ with gentle agitation followed by rinsing three times with sterile distilled water. After that, the seeds were surface sterilized in $50 \%$ (v/v) commercial bleach (approximately $5 \% \mathrm{NaOCl}$ ) for 30 min with agitation, then rinsed with sterile distilled water five times. Sterilized seeds (eight seeds/ Petri dish) were then cultured in Petri dishes containing $25 \mathrm{ml}$ callus induction medium (CIM) which included MS basal medium (Murashige and Skoog 1962) supplemented with $2 \mathrm{mg} \mathrm{l}^{-1}$ 2,4-D (2,4-dichlorophenoxyacetic acid), $30 \mathrm{~g} \mathrm{l}^{-1}$ sucrose and solidified with $3 \mathrm{~g} \mathrm{r}^{-1}$ Phytagel. The $\mathrm{pH}$ was adjusted to 5.8 before autoclaving. The Petri dishes were sealed with Nescofilm and incubated at $27 \pm 1^{\circ} \mathrm{C}$ in the dark for four weeks before callus induction responses were assessed. Ten Petri dishes were used per replication for each genotype. After four weeks of incubation, only embryogenic calli were selected from the cultures and transferred to fresh medium (CIM) for multiplication. Subculture was carried out once every 2 weeks. Callus induction frequency of each genotype was calculated as follows:

$\begin{gathered}\text { Callus induction } \\ \text { frequency }(\%)\end{gathered}=\frac{\text { Total number of seeds producing embryogenic callus }}{\text { Total number of seeds cultured }} \times 100$

\section{Measurement of Callus Growth}

Four-week old embryogenic calli were placed into a tube containing $10 \mathrm{ml} \mathrm{CIM}$. Eight tubes were used for each genotype for each replication. After one month, data on fresh weight gain of callus for each genotype was determined as follows:

$$
\text { Callus growth }(\%)=\frac{\text { Final fresh weight of cailus }- \text { Initial fresh weight of callus }}{\text { Initial fresh weight of callus }} \times 100
$$

\section{Composition of Fiegeneration Medium (RM)}

Three regeneration media were used; they were designated as RMI, RMII and RMIII. In all cases, MS salts were used as a basal component of the media tested. The only difference between the three media was in hormonal combination: RMl medium contained $2 \mathrm{mg} \mathrm{l}^{-1}$ BAP (6-benzylaminopurine), $1 \mathrm{mg}$ $I^{-1} \mathrm{NAA}$ ( $\alpha$-naphthalene acetic acid) and $1 \mathrm{mg} \mathrm{I}^{-1}$ Kinetin; RMII medium contained $2 \mathrm{mg} \mathrm{l}^{-1} \mathrm{BAP}, 0.5 \mathrm{mg} \mathrm{l}^{-1} \mathrm{NAA}$, and RMIII medium contained $4 \mathrm{mg} \mathrm{l}^{-1} \mathrm{BAP}, 0.5 \mathrm{mg} \mathrm{l}^{-1} \mathrm{NAA}$ and $0.5 \mathrm{mg}$ $r^{-1}$ IAA (indoleacetic acid). Sucrose was added to all media at $30 \mathrm{~g} \mathrm{l}^{-1}$ and Phytagel at $3 \mathrm{~g} \mathrm{l}^{-1}$. The $\mathrm{pH}$ of the medium was adjusted to 5.8 before sterilization.

\section{Plant Regeneration}

For regeneration, eight-week old embryogenic calli were placed into glass tubes $(10 \times 2.5 \mathrm{~cm}$ diameter $)$, each containing $10 \mathrm{ml}$ medium from one of three regeneration media (RMI, RMII o: RMII). All such cultures were kept at $27 \pm 1^{\circ} \mathrm{C}$ under a $16 \mathrm{~h}$ photoperiod regime giving irradiance levels in the range of $55-62 \mu \mathrm{E} \mathrm{m}^{-2} \mathrm{~s}^{-1}$ at the bench surface. In total sixteen tubes were used per replication of each regeneration medium. Data on plantlet regeneration were collected 6 weeks after transfer of calli. The regeneration response of each genotype was calculated as follows:

Table 1. Indica rice genotypes used in this study for callus induction and plant regeneration.

\begin{tabular}{|c|c|c|}
\hline Genotype & Genetic background & Growing ecosystem \\
\hline $\mathrm{BR} 22$ & High yielding variety & Rainfed low land \\
\hline BR23 & High yielding variety & Rainfed low land \\
\hline BRRI dhan29 & High yielding variety & Rainfed low land \\
\hline BR5842-15-4-8 & Advanced breeding line & Irrigated \\
\hline $\mathrm{BR}(\mathrm{BE}) 6155-1-1$ & $\begin{array}{l}\text { Advanced breeding line } \\
\text { (Wide hybrid) }\end{array}$ & Tidal wet land \\
\hline BR1192-2B-35 & Advanced breeding line & Rainfed low land \\
\hline BR4766-3B-1 & Advanced breeding line & Rainfed low land \\
\hline IR19743-SC $10-9-2-3$ & $\begin{array}{l}\text { Advanced breeding line } \\
\text { (Salt tolerant somaclone) }\end{array}$ & Tidal wet land (saline) \\
\hline Nonabokra & Land race (Salt tolerant) & Tidal wet land (saline) \\
\hline Moulata & Land race & Tidal wet land (non-saline) \\
\hline Rajeshawri & Land race & Tidal wet land (non-saline) \\
\hline
\end{tabular}


$\begin{aligned} & \text { Plant regeneration } \\ & \text { frequency }(\%)\end{aligned}=\frac{\text { Total number of calli producing plants }}{\text { Total number of calli on the regeneration media }} \times 100$

\section{Scanning Electron Microscopy (SEM)}

Six-week old embryogenic calli from different rice genotypes grown on CIM were used for SEM. Calli were first fixed overnight with $3 \%$ glutaraldehyde in $0.1 \mathrm{M}$ phosphate buffer $\left(\mathrm{pH} \mathrm{7.0)}\right.$ at $8^{\circ} \mathrm{C}$ followed by tow washes in the same buffer, then dehydrated through a series of acetone solutions $(50,70$, 80 and $90 \%$ ) for $1 \mathrm{~h}$ each. The final dehydration was in three changes of $100 \%$ acetone for $1 \mathrm{~h}$. Dehydrated specimens were critically point dried and then mounted on aluminum stubs. The mounted specimens were coated with a very thin layer of gold. Finally the coated specimens were examined in a scanning electron microscope and photographs were taken if necessary using a camera attached to the microscope.

\section{Experimental Design and Statistical Analysis}

A completely randomized design with three replications per genotype was used in this study. Analysis of variance (ANOVA) was done for the assessment of variation due to genotypes and other parameters used in this study. Duncan's multiple range tests (DMRT) was used to show the differences between mean values for callus induction frequency and callus growth rate of 11 rice genotypes. Correlation coefficients between different tissue culture responses were calculated. Means and standard errors of means (S.E.) were also calculated.

\section{Results}

\section{Initiation of Callus}

Mature dehusked rice seeds cultured on callus induction medium developed coleoptiles after 2-3 days but these structures later ceased to grow. Callus was initiated on the scutellum of the seed embryo within 1 week (Fig.1A), and grew in size over the next 3 weeks on the induction medium. Both embryogenic and non-embryogenic calli were initiated at the surface of the mature seed embryo. However, callus induction frequency was calculated on the basis of embryogenic callus production from the mature embryos. Embryogenic callus (Fig. 1B) was usually light yellow to white in color, dry, compact and nodular in appearance while non-embryogenic callus appeared watery, light yellow to $\tan$ and non-nodular. Callus induction frequency varied from $94.3 \%$ to $47.0 \%$. Significant differences $(\mathrm{P}<0.001)$ were detected between callus induction frequency in the 11 rice genotypes tested (Table 2). The highest rate of callus production was found in genotype BR5842-15-4-8 and the lowest in BR4766-3B-1. All three high yielding genotypes (BR22, BR23 and BRRI dhan29) had higher rates of callus induction frequency than low yielding genotypes, except Moulata (Table 2).

\section{Callus Growth}

Mean fresh-weight gain of callus from 11 rice genotypes are presented in the Table 2. Increases in fresh-weight gain varied from $407.6 \%$ to $663.8 \%$. The highest callus growth

Table 2. Callus induction frequency and callus growth of 11 Indica rice genotypes (Means \pm S.E.).

\begin{tabular}{lcc}
\hline Genotype & \% Callus induction frequency & $\begin{array}{c}\text { \% Callus growth } \\
\text { (fresh weight basis) }\end{array}$ \\
\hline BR22 & $82.7 \pm 8.0 \mathrm{ab}$ & $414.9 \pm 13.9 \mathrm{e}$ \\
BR23 & $90.0 \pm 2.7 \mathrm{a}$ & $654.0 \pm 18.6 \mathrm{a}$ \\
BRRI dhan29 & $89.0 \pm 3.21 \mathrm{a}$ & $663.8 \pm 13.3 \mathrm{a}$ \\
BR5842-15-4-8 & $94.3 \pm 2.0 \mathrm{a}$ & $465.6 \pm 16.2 \mathrm{dc}$ \\
BR(BE)6155-1-1 & $65.0 \pm 3.5 \mathrm{~cd}$ & $507.1 \pm 11.2 \mathrm{c}$ \\
BR1192-2B-35 & $76.3 \pm 4.3 \mathrm{bc}$ & $439.0 \pm 22.0 \mathrm{de}$ \\
BR4766-3B-1 & $47.0 \pm 3.1 \mathrm{e}$ & $504.9 \pm 11.6 \mathrm{c}$ \\
IR19743-SC10-9-2-3 & $55.3 \pm 3.0 \mathrm{e}$ & $651.1 \pm 16.0 \mathrm{a}$ \\
Nonabokra & $49.3 \pm 4.4 \mathrm{e}$ & $492.2 \pm 16.2 \mathrm{c}$ \\
Moulata & $89.3 \pm 2.4 \mathrm{a}$ & $407.6 \pm 12.0 \mathrm{e}$ \\
Rajeshawri & $51.0 \pm 2.5 \mathrm{e}$ & $567.1 \pm 15.8 \mathrm{~b}$ \\
\hline One-way ANOVA & $\mathrm{P}=<0.001$ & $\mathrm{P}=<0.001$ \\
\hline
\end{tabular}


was observed in a high yielding variety, BRRI dhan29 and lowest in a land race, Moulata. Genotypes differed significantly $(P<0.001)$.

\section{Regeneration of Plantlets and Soil Establishment}

After transfer of embryogenic calli onto the various regeneration media, green areas began to develop on callus surfaces within 2-3 week and then the simultaneous formation of shoots and roots (with a direct connection between shoot and root axis) occurred from these green areas (Fig.1D). At about the same time some calli of each treatment began to turn brown and die. In vitro regenerated plants were transferred into the soil, showed normal and healthy growth (Fig. 1E), and produced fertile seed after maturity (Fig.1F).

In regeneration, significant differences $(P<0.001)$ were observed between the genotypes and regeneration media. The genotype $x$ regeneration media interactions were also highly significant $(\mathrm{P}<0.001)$. Most genotypes gave the highest regeneration response on RMI medium, except $B R$ (BE)6155-1-1 and BR1192-2B-35 which showed highest responses on RMII and RMIII, respectively (Table 3). Of all the genotype/media combinations tested, BR22 showed the best results in RMI medium followed by Rajeshawri in RMI medium and BR (BE) 6155-1-1 in RMII medium. The highest plantlet regeneration response was therefore noticed on the RMI medium followed by the RMII and RMIII, media.

\section{Scanning Electron Microscopy}

Scanning electron microscopy revealed the early formation of somatic embryos (Fig.1C) in each genotype tested.

\section{Discussion}

In the present study, an efficient plant regeneration system in vitro was established from mature embryo-derived calli of some Indica rice genotypes with diverse genetic background. In our study, evaluating embryogenic callus formation, callus growth and plant regeneration potential, revealed significant difference $(P<0.001)$ between the 11 rice genotypes tested. But the absence of significant relationship between callus induction frequency and plant regeneration frequency clearly demonstrates that these characters are genetically independent. Thus BR23, BRRI dhan29, BR5842-15-4-8 and BR1192-2B-35 had a high callus induction frequency (Table 2), but low plant regeneration capacity (Table 3). $\mathrm{Cn}$ the other hand, BR22, BR4766-3B-1, IR19743-SC $10-9-2-3$ and Rajeshawri had a low callus induction frequency (Table 2), but high plant regeneration capacity (Table 3 ). This is in agreement with previous reports where embryogenic callus formation as well as plant regeneration is genetically determined as described for different cereals including rice (Hartke and Lörz 1989; Khanna and Raina 1998), wheat (Özgen et al. 1998) and barley (Lührs and Lcrz 1987). Therefore, suitable genotypes should be used to increase the plant regeneration frequency in rice tissue culture.

Large genotypic variations in callus growth and plant regeneration potential were detected among the rice genotype tested (Table 2 and 3 ). The callus growth was not correlated with the plant regeneration potential. Similar type of findings was observed in rice (Abe and Futsuhara 1986) and wheat (Özgen et al. 1998) tissue culture. In our study, cultures showed differences in callus growth and plant regeneration frequency: high capacity for both the traits, high capacity for callus growth and low for plant regene-

Table 3. Regeneration response of 11 Indica rice genotypes on different regeneration media.

\begin{tabular}{|c|c|c|c|}
\hline \multirow{2}{*}{ Rice genotype } & \multicolumn{3}{|c|}{ Percentage plant regeneration (Mean \pm S.E.) } \\
\hline & RMI & RMII & RMIII \\
\hline BR22 & $96.0 \pm 4.0$ & $92.0 \pm 4.0$ & $46.0 \pm 4.0$ \\
\hline BR23 & $29.3 \pm 4.3$ & $17.0 \pm 4.0$ & $13.0 \pm 0.0$ \\
\hline BRRI Dhan 29 & $58.7 \pm 4.3$ & $46.0 \pm 4.0$ & $37.7 \pm 7.2$ \\
\hline BR5842-15-4-8 & $50.3 \pm 7.2$ & $25.3 \pm 7.2$ & $50.0 \pm 0.0$ \\
\hline $\mathrm{BR}(\mathrm{BE}) 6155-1-1$ & $50.0 \pm 0.0$ & $79.3 \pm 4.3$ & $21.0 \pm 4.0$ \\
\hline BR1192-2B-35 & $37.7 \pm 7.2$ & $13.0 \pm 0.0$ & $42.0 \pm 4.0$ \\
\hline BR4766-3B-1 & $67.0 \pm 4.0$ & $46.0 \pm 4.0$ & $37.7 \pm 7.2$ \\
\hline IR19743-SC $10-9-2-3$ & $71.0 \pm 4.0$ & $25.3 \pm 7.2$ & $13.0 \pm 0.0$ \\
\hline Nonabokra & $29.3 \pm 4.3$ & $17.0 \pm 4.0$ & $17.0 \pm 4.0$ \\
\hline Moulata & $75.3 \pm 7.2$ & $33.7 \pm 4.3$ & $17.0 \pm 4.0$ \\
\hline Rajeshawri & $83.7 \pm 4.3$ & $13.0 \pm 0.0$ & $42.0 \pm 4.0$ \\
\hline
\end{tabular}

LSD $(5 \%)$ for genotype $\times$ regeneration media interaction $=13.02$

Data are the mean of three replicates each with 16 calli 


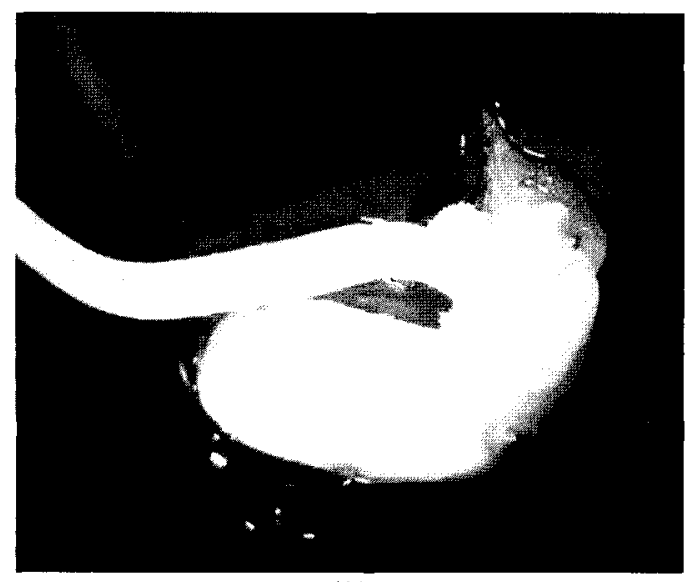

(A)

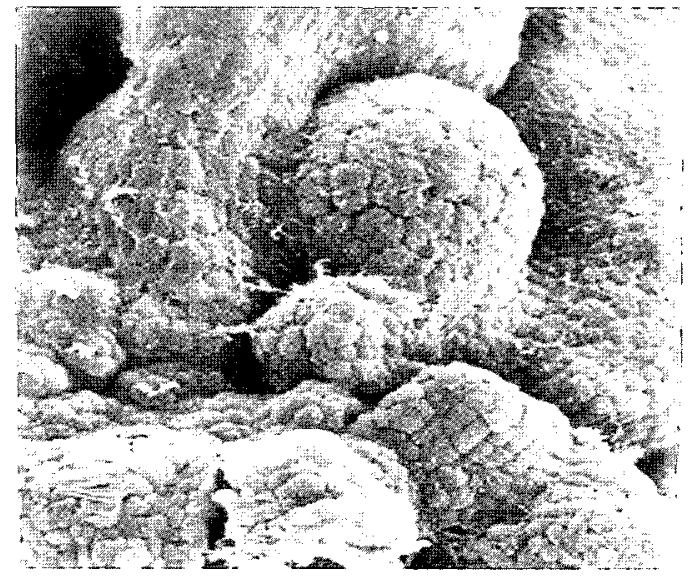

(C)

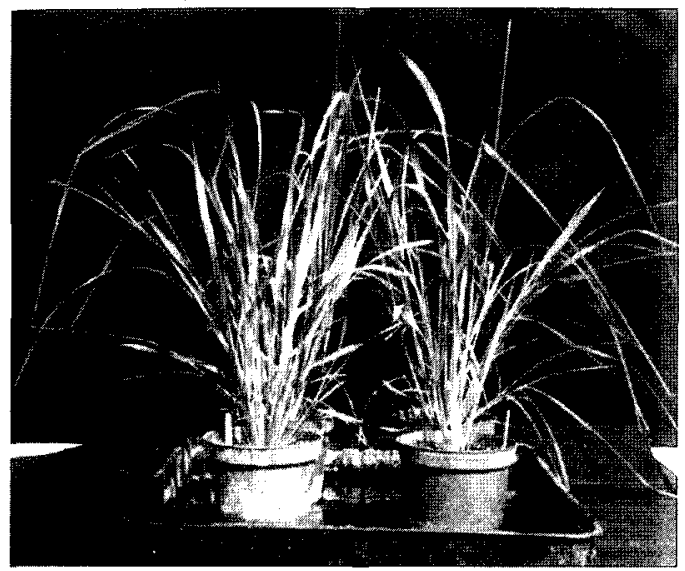

(E)

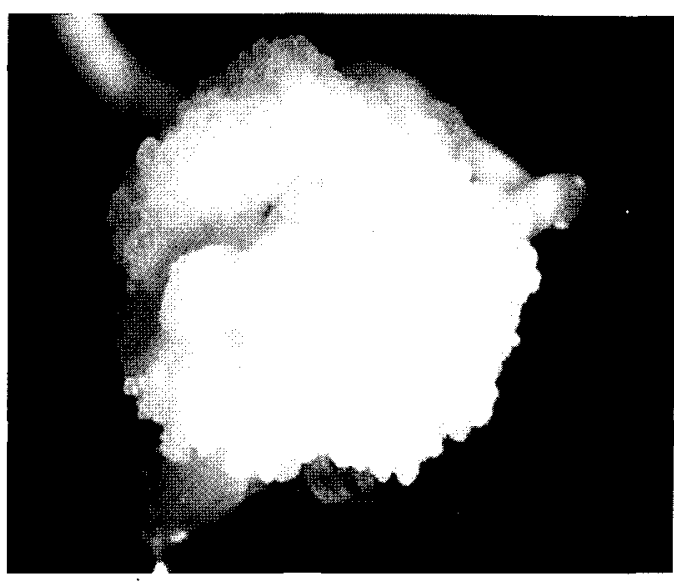

(B)

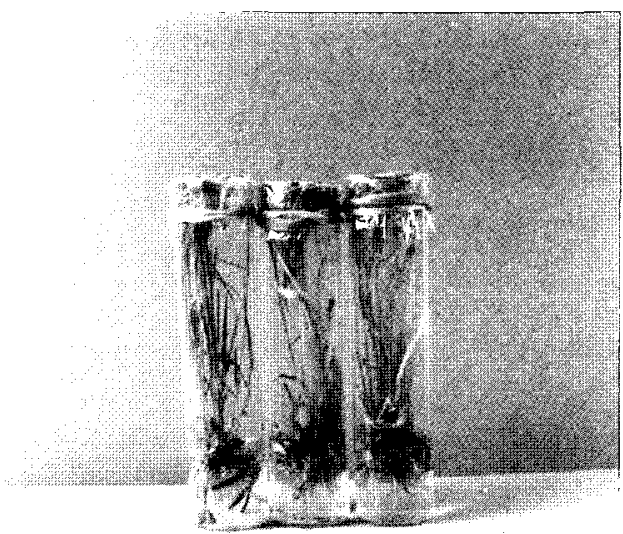

(D)

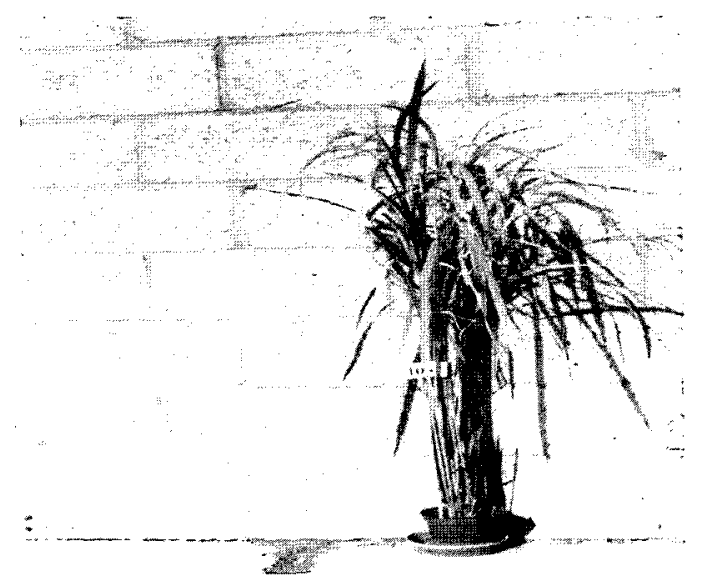

(F)

Figure 1. Plant regeneration from mature embryo-derived embryogenic calli, $A$, Callus induction from mature embryos after one week culture on callus induction medium. B, Embryogenic callus on callus induction medium after 4 weeks of culture. C, Scanning electron micrograph showing the early formation of somatic embryos in embryogenic callus culture (arrow, $\times 210$ ). $D$, Plant regenerated from somatic embryogenic callus. E, Rice-plant, six weeks after establishment in soil. F, A mature tissue culture-derived rice plant.

ration, low capacity for callus growth and high for plant regeneration, and low capacity for both the traits. These variations might be due to differences in the components and concentrations of endogenous phytohormones, and differences in the susceptibility to $2,4-D$ between the rice genotype tested, as reported in the growth of rice plant by Sundaru et al. (1983).

Although genotypic effects on plant regeneration from mature embryo culture of rice has been reported, the regeneration rate could be enhanced by using various combinations of auxin and cytokinin to the regeneration medium (Rueb et al. 1994; Kunanuvatchaidach et al. 1995; Lee at al. 2002). Kinetin found to enhance the shoot regeneration in rice callus culture (Raina 1989). Lee et al. (2002) reported that kinetin is more effective for shoot regeneration compared with BAP. They also reported that either of kinetin or 
BAP combined with NAA gave highest shoot regeneration frequencies. Although three different combinations of plant growth regulators used in our study, most of the genotypes showed highest shoot regeneration responses in the medium containing kinetin, BAP and NAA. However, exceptions were occurred in two rice genotypes among the eleven genotypes tested (Table 3 ). Therefore it could be said that depending on the genotype, an appropriate combination of cytokinin and auxin need to be determined for efficient shoot regeneration in rice callus culture. Similar types of observations were reported in rice (Pons et al. 2000, Lee et al. 2002). It is also apparent from this study that genotypic barriers could be overcome in many Indica rice genotypes by manipulation of plant growth regulators in the culture media used for plant regeneration. Hartke and Lörz (1989) and Kunanuvatchaidach et al. (1995) observed similar responses for development of in vitro plant regeneration system from mature embryo-derived calli of Indica rice.

In the present study, SEM observations demonstrated the early formation of rice somatic embryos (Fig.1C) in the embryogenic callus culture. Our results are, therefore, with the agreement of the finding of other workers (Abe and Futsuhara 1985, Hoque and Mansfield 2004) who reported that embryogenic callus cultures easily formed in rice, which readily gave rise to somatic embryo.

In conclusion, there were strong genotypic influences on callus formation, callus growth and plant regeneration. No significant correlations existed among the three culture responses suggesting that different genes or gene combinations may control the responses. The present study also showed that appropriate combination of plant growth regulators need to be used in plant regeneration media. to get highest success. The results provided here suggests that embryogenic calli obtained from mature embryos is a very good source material for efficient plant regeneration in vitro, which is key step in gene transfer and plant regeneration in rice biotechnology.

\section{References}

Abe T, Futsuhara $Y$ (1985) Efficient plant regeneration by somatic embryogenesis from root callus tissues of rice (Oryza sativa L.). J Plant Physiol 121: 111-118

Abe T, Futsuhara $Y$ (1986) Genotypic variability for callus formation and plant regeneration in rice (Oryza sativa L.). Theor Appl Genet 72: 3-10

Chu QR, Croughan T P (1990) Genetics of plant regeneration in immature panicle culture of rice. Crop Science 30: 1194-1197

Hartke S, Lörz H (1989) Somatic embryogenesis and plant regeneration from various Indica rice (Oryza sativa L.) genotypes. J Genet Breed 43: 205-214

Hoque EH (2002) Development of Agrobacteriummediated transformation of rice (Oryza sativa L.) genotypes grown in Bangladesh. PhD thesis, University of London, UK

Hoque EH, Mansfield JW (2004) Effect of genotype and explant age on callus induction and subsequent plant regeneration from root-derived callus of Indica rice genotypes. Plant Cell Tiss Org Cult 78: 217-223

Jain RK (1997) Elfect of some factors on plant regeneration from Indica rice cells and protoplasts-a review. Indian J Expt Biol 35: 323-331

Khanna HK, Raina SK (1998) Genotype × culture media interaction effects on regeneration response of three Indica rice cultivars. Plant Cell Tiss Org Cult 52: $145-153$

Kunanuvatchaidach R, Godwin ID, Adkins SW (1995) High efficiency plant regeneration from callus induced on mature Indica rice caryopses. Aust $J$ Bot 43: 337-348

Lee $\mathrm{K}$, Jeon $\mathrm{H}$, Kim M (2002) Optimization of a mature embryo-based in vitro culture system for highfrequency somatic embryogenic callus induction and plant regeneration from Japonica rice cultivars. Plant Cell Tiss Org Dult 71: 237-244

Lörz H, Göbel E, Brown P (1988) Advances in tissue culture and progiess towards genetic transformation of cereals. Plant Breed 100: 1-25

Lührs R, Lörz H (1987) Plant regeneration in vitro from embryogenic cultures of spring- and winter-type barley (Hordeum vulgare L.) varieties. Theor Appl Genet 75: 16-25

Murashige T, Skoog F (1962) A revised medium for rapid growth and bioassays with tobacco tissue cultures. Physiol Plant 15: 473-497

Özgen M, Türet M, Altinok S, Sancak C (1998) Efficient callus induction and plant regeneration from mature embryo culture of winter wheat (Triticum asetivum L.) genotypes. Plant Cell Rep 18: 331-335

Pons MJ, Marfà V, Melé E, Mesșeguer J (2000) Regeneration and genetic transformation of Spanish rice cultivars using mature embryos. Euphytica 114: 117-122

Raina SK (1989) Tissue culture in rice improvement: status and potential. Adv Agron 42: 339-398.

Rueb S, Leneman $M$, Schilperoot RA, Hensgens LAM (1994) Efficient plant regeneration through somatic embryogenesis from callus induced on mature rice embryos (Oryza sativa L.). Plant Cell Tiss Org Cult 36: $259-264$

Sundaru M, Baba I, Tanabe T, Tamai F, Motoda $Y$ (1983) Varietal difference of Indonesian rice plants in their susceptibility to $2,4-D$ injury and interrelationships with Ethylene. Jpn J Crop Sci 52: 323-330

Toenniessen GH (1991) Potentially useful genes for rice genetic engineering. In: Khush GS, Toenniessen GH (eds), Rice Biotechnology, CAB International and IRRI, Wallingford/Manila, pp 253-280

Vasil V, Srivastava V, Castillo AM, Fromm MR, Vasil IK (1993) Rapid production of transgenic plants by direct bombardment of cultured immature embryos. Bio/ echnol 11: 1553-1558 